\title{
Formatos con texto, imagen y sonido en campañas de comunicación persuasiva móvil
}

\section{Formats with text, image and sound in mobile persuasive communication campaigns}

\author{
José Ignacio Niño González \\ Profesor Asociado (Universidad Complutense de Madrid) \\ María Luisa García Guardia \\ Profesora Contratada Doctor (Universidad Complutense de Madrid) \\ Antonio Alcaraz Lladró \\ Doctor (Universidad Complutense de Madrid)
}

Fecha de recepción: 22 de diciembre de 2013

Fecha de revisión: 18 de enero de 2014

Para citar este artículo: Niño González, J.I., García Guardia, M.L. \& Alcaraz Lladró, A. (2014): Formatos con texto, imagen y sonido en campañas de comunicación persuasiva móvil, Icono 14, volumen (12), pp. 267-292. doi: 10.7195/ri14.v12i1.631 


\section{Resumen}

El marketing mobile se ha convertido en los últimos años en una acción publicitaria de peso en el campo de las comunicaciones persuasivas y en la puesta en marcha de las estrategias de comunicación de las organizaciones. Este desarrollo no hubiera sido posible sin la rápida evolución de la tecnología, y en concreto, de los terminales móviles. Ahora bien, si la tecnología es un elemento imprescindible en el desarrollo de los medios de comunicación social, no lo es menos la evolución de sus contenidos. Se puede entender la creatividad como la manifestación expresiva y la forma la razón tecnología, siendo dificil justificar la una sin la otra en el contexto de la comunicación persuasiva actual (Arroyo, 2004).

En este artículo científico se pretende demostrar la importancia del componente expresivo, directamente dependiente de la existencia de un terminal móvil que redefine la relación hombre-máquina en la comunicación persuasiva.

Palabras clave: Componente expresivo - Marketing mobile - Diseño - Eficacia - Formato texto/imagen/sonido.

\section{Abstract}

The mobile marketing has become in the last years an important advertising instrument in the field of persuasive communications and in the communication strategies of the organizations. This development would not have been possible without the rapid evolution of technology, and in particular mobile terminals. However, if the technology is an essential element in the development of social media, it is no less the evolution of its contents. Creativity can be understood as the expressive manifestation and the format the technology reason, being difficult to justify one without the other in the context of the current persuasive communication (Arroyo,2004).

This article aims to demonstrate the scientific importance of expressive component, directly dependent on the existence of a mobile terminal that redefines the human-machine relationship in persuasive communication.

Key Words: Expressive component - Mobile marketing - Design - Efficiency - Text/ image/sound format. 


\section{Introducción}

El marketing mobile se ha convertido en los últimos años en una acción publicitaria de peso en el campo de las comunicaciones persuasivas y en la puesta en marcha de las estrategias de comunicación de las organizaciones. Este desarrollo no hubiera sido posible sin la rápida evolución de la tecnología, y en concreto, de los terminales móviles. Ahora bien, si la tecnología es un elemento imprescindible en el desarrollo de los medios de comunicación social, no lo es menos, la evolución de sus contenidos en esta década en la que nos encontramos. Se puede entender la creatividad como la manifestación expresiva y la forma la razón tecnológica, siendo difícil justifica la una sin la otra en el contexto de la comunicación persuasiva actual (Arroyo, 2004).

Los contenidos expresivos nacidos de los recursos narrativos beben su inspiración en figuras retóricas basadas principalmente en la repetición -un ejemplo representativo es la metáfora-, y dan significado a los mensajes de carácter expresivo, convirtiéndose en objeto de estudio académico y profesional a desarrollar desde el ámbito científico. La nueva publicidad es el resultado de la evolución del consumidor, y su participación en la creación de contenidos multimedia. El sujeto quiere experiencias, desea contenidos de marca o Branded Content (Carrillo y Castillo, 2005).

El símbolo corporativo que mayormente aspira a ser globalizado recurre a los elementos retóricos existentes desde hace siglos, y es en ellos en los que se encuentra la inspiración y explicación de los esquemas narrativos contemporáneos persuasivos (García García, Llorente Barroso y García Guardia, 2010) que forman de la metodología de trabajo de los diseñadores, consciente o inconscientemente.

En este artículo científico se pretende demostrar la importancia del componente expresivo -uso de formato texto/imagen-, directamente dependiente de la existencia de un terminal móvil que redefine la relación hombre-máquina en la comunicación persuasiva de las organizaciones. 


\subsection{Eficacia y comunicación eficaz}

Cuando se investiga un área de conocimiento como el publicitario, es conveniente tener en cuenta que el mensaje es de índole persuasivo: a la hora de transmitir un contenido hay que ser consciente de que no es suficiente con "dar la información". El receptor sólo retiene un pequeño porcentaje formal o expresivo cuando recibe un mensaje publicitario; y el resto proviene de la comunicación no verbal (gestos, posición, entonación, expresiones, etc.) (Mourelle de Lema, 2003). Por lo tanto, hay que ser consciente de que existen otros factores que inciden en la transmisión del mensaje, y que pueden jugar en contra si no se utilizan de la forma más adecuada.

Cuando se trata de analizar aspectos relacionados con los diseños publicitarios y los elementos que lo componen, hay que tener en cuenta que el mensaje publicitario busca como fin último la eficacia; es decir, que el mensaje no solo llegue al receptor, sino que lo haga de la manera deseada. A la hora de llevar a cabo una comunicación eficaz, hay que tener en cuenta lo que queremos decir, y también cómo lo vamos a decir. Por ello, se debe destacar los siguientes aspectos:

- Cómo está el sujeto consigo mismo: Autoconocimiento, autocontrol y automotivación. Si yo, como emisor, no creo en lo que estoy diciendo o no tengo ni idea de lo que estoy hablando, será imposible que la comunicación llegue a ser eficaz; es decir, que consiga un objetivo concreto.

- Cómo está con los demás, es decir:

- Empatía y capacidad de escucha, para que una comunicación sea eficaz hay que saber ponerse en el lugar del otro e intentar identificar sus necesidades mediante una escucha activa; esto es, no limitarse a oír lo que dicen los demás, sino saber analizar ese mensaje y sacar algo de «beneficio» para ambas partes.

- Habilidades sociales: Son las herramientas de las disponen los seres humanos a la hora de relacionarnos con otros individuos.

- Adaptación al interlocutor: Saber adaptar el mensaje a uno mismo y a los demás. 
- Personalidad: Aprender a ser flexibles y amoldarnos a las necesidades y características de las personas.

- Asertividad: Defender nuestros intereses siempre sin llegar a ofender a la otra persona.

Los aspectos anteriores tienen relevancia a la hora de emitir un mensaje, y sólo en este contexto puede llevarse a cabo una comunicación eficaz.

A la hora de hablar de eficacia, no se debe confundir con una comunicación eficiente, aunque funcionan de forma muy similar en los casos en los que se elabora un mensaje persuasivo. La comunicación eficaz es aquella que permite alcanzar los objetivos establecidos realizados de forma adecuada, mientras que la comunicación eficiente es la que busca alcanzar esos mismos objetivos establecidos, pero utilizando la menor cantidad de recursos posibles. En el caso concreto de esta investigación, eficacia mediante el uso de los componentes expresivos formados con texto e imagen.

\subsection{Comunicación persuasiva}

Dentro de las Teorías de la Comunicación Humana se encuentran aquellas que son las que se refieren a los Medios de la Comunicación Social (Dance, 1973). En este campo se encuentra la denominada comunicación persuasiva, aquella que intenta persuadir y convencer al receptor. La persuasión "no es algo que una persona ejerza sobre otra, indica la autora K. Reardon, sino que es un medio por el cual las personas colaboran unas con otras en la conformación de sus versiones de la realidad, privadas o compartidas" (Reardon, 1981:21).

Se puede definir este tipo de comunicación como la intención consciente de un individuo que pretende modificar la conducta de otro individuo o grupo a través de un mensaje y con la utilización del lenguaje. La publicidad vive por naturaleza en el ámbito de la comunicación persuasiva, y su objetivo es «convencer» a los receptores para que adquieran determinados productos o servicios. El discurso publicitario tiene que ser hábil, y manejar con destreza todos los recursos a su alcance; especialmente, aquellos que recaen en el dominio del lenguaje y en la fuerza de la palabra.

DOI: ri14v12i1.631 | ISSN: 1697-8293 | Año 2014 Volumen 12 N¹ | ICONO14 
Por tanto, para entender la publicidad, hay que comprender cómo se articula la persuasión, y para ello es necesario abordar el campo de conocimiento delimitado por la retórica:

"La definición más antigua que conozco de la retórica es una metáfora 'personificadora' que dice así: la Retórica es 'artesana de la persuasión', peithoûs demiourgós, así justamente, en griego antiguo, porque los antiguos griegos fueron quienes inventaron la retórica, el nombre de la retórica y hasta la historia de la invención de la retórica" (López, 2000:12).

La Retórica tiene su origen en la Grecia Clásica, y nace como un arte vinculado estrechamente a la democracia que permitía a los ciudadanos defenderse en público con las palabras y decir lo que querían sin traspasar los límites establecidos por la comunidad. Por tanto, a partir de este momento los individuos dispondrán de una herramienta con la que expresar sus reivindicaciones e intentar "convencer" a los gobernantes de la legitimidad de las mismas.

Actualmente, la publicidad recoge la herencia clásica del arte de la persuasión, y propone sus elaboraciones publicitarias con objeto de «influir» emocionalmente en los destinatarios. Cuando las estructuras retóricas están presentes en un discurso persuasivo, siempre se busca modificar la conducta del receptor y se incorpora una intención. Como afirma Francisco García García, la retórica tiene capacidades incuestionables:

"De lo que no cabe duda es de su eficacia para comunicar, convencer, persuadir, argumentar y expresar estéticamente" (García, 2005).

Ahora bien, es fundamental tener en cuenta que en la actual sociedad de la información, la realidad de la comunicación persuasiva está cambiando debido al impacto que tiene sobre ella la aparición de las nuevas tecnologías. Internet propiciará un cambio radical que afectará de manera profunda no solo a la publicidad sino a las formas de comunicación en general. Para la comunicación persuasiva este innovador marco tecnológico delimita un nuevo medio en el que las reglas cambian y esta ya no tendrá que buscar ser eficaz ante grandes 
grupos de potenciales consumidores dispuestos a dejarse convencer por argumentos generados unilateralmente por el emisor de la comunicación. Ahora estamos en un escenario en el que tendrá que ser capaz de convencer a individuos identificados, a los que solo les interesa recibir impactos publicitarios que tengan un alto grado de afinidad con sus gustos personales y que además sean contenidos en los que el receptor haya participado en su elaboración. Pero si hay alguna seña de identidad que hace que las nuevas tecnologías sean un campo de inmenso potencial para la publicidad sin lugar a dudas es su capacidad interactiva. La posibilidad de establecer un diálogo personalizado en tiempo real con el receptor abre enormes vías de explotación, pero también modifica las formas que tiene que adoptar la persuasión. No es lo mismo persuadir a masas anónimas comunicacionalmente pasivas que se comportan de un modo globalizado, que persuadir de forma particular a individuos que únicamente se mostraran reactivos ante argumentos persuasivos personalizados y que además participan de forma activa mediante el dialogo en la construcción de los contenidos.

La comunicación persuasiva en el siglo XXI se puede definir como el arte de la "persuasión segmentada" que se fundamenta en un exhaustivo conocimiento del individuo al que se le endosa la comunicación. Ya no podemos hablar de una modalidad de persuasión masiva igual para todos, estamos en presencia de una persuasión "a medida". Como ya hemos reflejado, los nuevos medios digitales con su capacidad para la interacción aportan a la comunicación una condición fundamental en el proceso de persuasión, pero a esta suma otras características propias de su naturaleza digital que permiten realizar campañas muy eficientes con niveles de inversión reducidos y que desarrollaremos en el siguiente apartado dedicado a la comunicación móvil.

El potencial que ofrecen las nuevas tecnologías a la publicidad es extraordinario, aunque su trayectoria no ha hecho más que empezar. Su evolución se materializa minuto a minuto y es difícil pronosticar cómo será la publicidad en los próximos años, aunque parece evidente que el avance continuará y veremos cómo se desarrollan innovadoras prestaciones.

DOI: ri14v12i1.631 | ISSN: 1697-8293 | Año 2014 Volumen 12 N¹ | ICONO14 
En definitiva, podemos decir que la comunicación persuasiva tiene que ser capaz de adaptarse a los cambiantes retos que plantean los nuevos medios de comunicación tecnológicos, y estar preparada para comprender los mecanismos por los que estos se mueven. Indudablemente, el contenido persuasivo en formato texto/ imagen continuará con su misma estructura, pero necesitará dominar las claves que posibilitan desarrollar están nuevas formas de modo eficaz en los entornos digitales.

\subsection{Comunicación móvil}

El desarrollo tecnológico de los últimos años culmina en la tecnología inalámbrica y en la influencia que esta ha tenido para cambiar aspectos fundamentales en la forma de relacionarse en la sociedad actual. La conocida como "revolución móvil" ha conseguido que los individuos estén conectados desde cualquier punto en el que se encuentren dotándoles de una movilidad que influye en su estilo de vida, su manera de relacionarse y comunicarse con los demás y como no, en su forma de trabajar:

"La tecnología móvil o inalámbrica es exactamente lo que su nombre implica, es decir, es una tecnología portátil que no requiere de cables conectados y que cuenta con gran variedad de dispositivos que soportan este tipo de conexiones tales como ordenadores portátiles, ordenadores de sobremesa, PDAs, GPSs, TPVs o teléfonos móviles entre los más extendidos" (Arroyo, 2004).

El éxito de las tecnologías móviles se ha basado en su facilidad para dar a entender a los usuarios las grandes ventajas que estas les aportan. El teléfono móvil es el gran exponente de esta nueva realidad, un dispositivo con una presencia tan fuerte en nuestras vidas que prácticamente nadie se plantea vivir sin él. Nunca en la historia de la humanidad, una tecnología, ni siquiera internet, ha tenido el nivel de penetración y adopción que ha experimentado el teléfono móvil. El ratio de penetración mundial es categórico: 6.766 millones de líneas móviles en 2012 y para 2017 se estima que habrá más de 9.000 millones $^{1}$.

ICONO14 | Año 2014 Volumen 12 NN$^{\circ} 1$ | ISSN: 1697-8293 | DOI: ri14v12i1.631 
En la actualidad las ciudades están llenan de individuos con todo tipo de dispositivos móviles que les permiten realizar múltiples tareas en cualquier momento: navegar por internet, hacer una transferencia cuando van en el autobús, consultar el correo electrónico, ver la televisión, entrar en su red social, oír su música favorita, etc., en resumen, un inmenso abanico de posibilidades que día a día es más amplio y que contribuye a facilitar la vida de los usuarios. Cada individuo dispone de un instrumento único e intransferible, que personaliza a su gusto y al que sólo tiene acceso el mismo. Es su ventana personal y a través de ella se comunica y recibe información, pero también consume servicios y productos de muy diferente índole. El dispositivo móvil no es tan solo una herramienta de comunicación con muchas funcionalidades, también es un instrumento con innegables capacidades mediáticas. Y es en esta línea, en su condición de medio de comunicación, en el que la publicidad tiene que trabajar para explotar sus posibilidades. Como sistema de comunicación persuasiva, la publicidad tiene que crear vínculos con cualquier medio innovador que le ofrezca la opción de llevar con eficacia mensajes publicitarios a potenciales consumidores. Y esta relación es aún más importante si pensamos que hablamos de un medio que se fundamenta en una tecnología de última generación que tiene una presencia especialmente grande en el segmento formado por los "nativos digitales", pilares básicos de la sociedad digital.

A nivel publicitario el siglo XXI se caracteriza por el énfasis en desarrollar modalidades de comunicación persuasivas personales, ya que como hemos visto son las que mejor satisfacen las demandas de los consumidores y además permiten una mejor medición de su eficacia. La publicidad "personal" tiene en las tecnologías móviles un aliado perfecto a través del teléfono móvil, puesto que permite llegar individualmente a los consumidores que exigen personalización. La publicidad nunca ha tenido ante sí un medio que le permita de un modo tan eficaz transmitir mensajes personalizados adaptados al gusto del receptor, interaccionar con él, saber cuál es su respuesta y dialogar con él en tiempo real. Hasta el momento, solo un ordenador conectado a internet ofrecía estas opciones, pero ahora se añade una variable que permite conseguir esta relación en "movilidad", es decir, en movimiento y sin limitaciones de espacio. Y aunque hoy en día, gracias al desarrollo de las tecnologías inalámbricas sea posible conectar un ordenador portátil a internet desde cualquier punto gracias a las redes wifi, las propias limitaciones de tamaño,

DOI: ri14v12i1.631 | ISSN: 1697-8293 | Año 2014 Volumen 12 N¹ | ICONO14 
peso y conectividad hacen que el teléfono móvil sea el dispositivo que ofrece más posibilidades de desarrollo ya que todo el mundo tiene uno a mano. Es personal, se lleva conectado puesto que la opción de llamar o recibir llamadas está siempre presente, pero es que además los actuales servicios de internet móvil permiten disponer en el teléfono de las mismas opciones que da un ordenador conectado a la red fija de internet y por tanto hablamos de un soporte con grandes perspectivas para la publicidad.

No sé puede cuestionar su capacidad interactiva, sus posibilidades para realizar transacciones en cualquier lugar o la riquísima información que se puede obtener del individuo que lo usa, pero es que además pone al alcance de la publicidad un sistema de medición idóneo. Este es un factor de esencial importancia para la publicidad, ya que desde que se comenzaron a realizar las primeras campañas de comunicación publicitaria siempre ha sido un objetivo prioritario disponer de métodos precisos de medición de la eficacia. La industria publicitaria necesita conocer cómo influye su actividad sobre los patrones de comportamiento de los consumidores, no sólo desde una perspectiva de mejora del proceso, sino como argumento "justificativo" para demostrar a los anunciantes como la inversión en publicidad es un arma definitiva para ganar posiciones en el mercado:

"Without the right measurement, we really don't know how well our efforts work. We need a method to determine the effectiveness of our efforts" (Stengal, 2004) ${ }^{2}$.

Las empresas demandan métodos para medir la eficacia de sus campañas, por lo que es básico disponer de herramientas de medición consistentes. En este sentido hay que destacar de forma muy especial la capacidad que presenta la publicidad digital para ser medida. Frente a fórmulas convencionales que obligaban a comprar espacios masivos en base a datos de proyección de audiencias, internet móvil pone a disposición de los clientes un sistema en el que se paga por cada individuo que interactúa con el anuncio contratado conocido como pago por click. Esta nueva forma de comprar publicidad permite conocer en detalle cómo funcionan las campañas y por tanto poder tener un dato preciso sobre el retorno de la inversión o en sus siglas inglesas ROI (return on investment). En esencia tenemos a nuestro al- 
cance unas métricas que nos informan con nombres y apellidos de cómo funcionan nuestras acciones y de este modo podemos conocer los valores positivos generados para las mismas.

En definitiva, como hemos visto, internet móvil desde sus primeros pasos es un medio que ha revolucionado el ámbito de la publicidad en muchos aspectos. Si a su capacidad interactiva unimos su medición en tiempo real, su menor coste y unas audiencias cada vez más personalizadas entenderemos porque es el medio con mayor tasa de crecimiento anual en inversión publicitaria.

La publicidad ha comprendido que las nuevas tecnologías están modificando los principios sobre la que esta se fundamentaba, su foco ha cambiado y ahora tiene que dirigirse hacia consumidores individuales y no masivos. Estos consumidores cada vez son más exigentes, no les gusta parecerse a los demás y requieren comunicaciones que reafirmen su personalidad. Por otro lado, si la publicidad ya no apunta a una masa anónima sino a un consumidor identificado, será mucho más fácil saber qué grado de eficacia tiene la comunicación, ya que se conocerá como responde individualmente y por tanto será fácil ir depurando los mecanismos que conducen hacia una comunicación persuasiva capaz de alcanzar los objetivos alcanzados.

\subsection{El contenido de la telefonía móvil}

Los contenidos publicitarios conviven con otros que no tienen una esencia estrictamente persuasiva. Concretamente, cuando se analiza un segmento como el de los contenidos en la telefonía móvil, se encuentran diferentes tipos de productos a los que se acceden mediante las populares descargas, productos diseñados con variados objetivos (Katz, E. \& Aarhus, M., 2002). Si algo tienen claro todos los actores que intervienen en la cadena de valor creada en torno a la industria del teléfono móvil, es que no se pueden dejar escapar oportunidades que contribuyan a aumentar los ingresos. Es por ello, por lo que los fabricantes, operadores, agencias, desarrolladores y empresas buscan modelos de ingresos compartidos en los que las aplicaciones son creadas pensando en su explotación publicitaria. Cualquier nuevo contenido se diseña para que, de algún modo, pueda tener además de su propio ingreso, otros mediante vías publicitarias.

DOI: ri14v12i1.631 | ISSN: 1697-8293 | Año 2014 Volumen 12 N¹ | ICONO14 
Por lo tanto, se puede decir que todos los contenidos que se desarrollan para ser insertados en la telefonía móvil son susceptibles de soportar publicidad contextualizada, lo que conlleva unificar su aspecto comercial.

Es conveniente hacer énfasis sobre la siguiente puntualización: no se debe confundir la descarga de contenidos con carácter publicitario con el desarrollo del marketing móvil. Aunque resulte evidente, descargarse una melodía publicitaria en el teléfono móvil es una acción puntual aislada que pretende generar un ingreso rápido, pero nunca puede ser considerada como una acción de marketing móvil. En todo caso, se puede contemplar como un recurso que entronca dentro de una estrategia global, pero no tiene ninguna trascendencia comunicacional por sí sola.

Si se analiza el valor de los contenidos, no se puede perder de vista el papel que juegan los usuarios de los nuevos medios, y cómo la publicidad ha de saber posicionarse respecto a este papel activo de los receptores de la comunicación:

"Uno de los rasgos esenciales en el que es importante insistir, y que deriva de la experiencia que han adquirido los usuarios de los New Media, tiene que ver con la capacidad ya apuntada de que los nuevos medios permiten a los usuarios convertirse en productores de contenidos audiovisuales $y$, de ese modo, abandonan el rol de receptores de información para convertirse en auténticos elaboradores que difunden su propia información audiovisual" (García, Gértrudix, García, 2009:25).

El contenido de los mensajes publicitarios, independientemente del medio empleado, construyen narraciones cuyo fin es la persuasión a través de diferentes herramientas del lenguaje.

\section{Métodos}

\subsection{Objeto formal}

Esta investigación tiene por objeto analizar el peso del elemento expresivo mediante el uso de componentes textuales y visuales cuando se diseña una comunica- 
ción publicitaria, teniendo en cuenta que el objetivo es obtener resultados eficaces al finalizar las campañas. No es un trabajo que quiera abordar el uso genérico del teléfono móvil o conocer los principios técnicos de la telefonía móvil, es un estudio que pretende investigar parámetros expresivos publicitarios que se encuentran en este dispositivo y establecer cómo se utilizan las capacidades tecnológicas para articular acciones de comunicación persuasiva.

\subsection{Preguntas de investigación}

Las preguntas claves planteadas en esta investigación son:

- ¿Qué mensajes publicitarios se entienden mejor en el teléfono móvil en función de su componente expresivo - texto, imagen y sonido-?

- ¿Se recuerda de igual modo la publicidad recibida en el teléfono móvil al margen de su componente expresivo, o este modifica el grado de recuerdo?

\subsection{Objetivos}

- Establecer que influencia tienen los componentes expresivos - textuales, visuales y sonoros - de los mensajes publicitarios en el grado de comprensión de estos por parte de los consumidores.

- Analizar si los mensajes publicitarios recibidos en el teléfono móvil se recuerdan en mayor o menor medida en función de su componente expresivo.

\subsection{Hipótesis}

- La frecuencia de recepción de anuncios publicitarios varía según la forma en que llegan al terminal.

- El grado de recuerdo de los mensajes publicitarios en el móvil varía en función de los componentes expresivos.

- El grado de comprensión de los mensajes publicitarios en el móvil varía en función del componente expresivo y del género. 
- Existe una variación significativa entre hombres y mujeres en cuanto a la recepción de los componentes -texto, imagen y sonido- de los mensajes publicitarios.

\subsection{Metodología}

Para llevar a cabo un análisis pertinente del objeto de estudio de este trabajo, se plantea realizar una estrategia de investigación que utiliza técnicas cuantitativas.

\section{Fase cuantitativa}

Permitirá lograr precisión en el análisis de los resultados y describir la relación estadística entre variables que dé respuesta a las preguntas planteadas.

\section{Encuesta de opinión}

Mediante una encuesta de opinión analítica, se explicará cómo se relacionan los usuarios de teléfonos móviles con los usos publicitarios que se dan en su terminal.

Para desarrollar el estudio, se ha seleccionado una muestra no probabilística accesible que ha participado de modo voluntario y que representa al perfil genérico de usuarios de teléfonos móviles.

Al grupo de referencia se le ha sometido a un cuestionario de respuesta cerrada de selección múltiple, basándose en la escala de Likert. Las preguntas pretenden que el encuestado muestre su grado de acuerdo o desacuerdo en una escala de $0 \mathrm{a}$ 5 respecto a la propuesta planteada. Todas las preguntas incorporan aspectos relevantes de las variables en estudio para su medición. Los encuestados solo pueden elegir una opción en cada pregunta (Wimmer, 1996).

Para facilitar el cumplimiento del cuestionario, todas las preguntas están construidas de un modo que permite responderlas de forma sencilla. Aunque son muchas las áreas de interés que el mencionado formulario aborda, se condensó al máximo para no provocar abandonos por ser demasiado extenso. 
Se buscó una forma de entrevista que fuese operativa y directa, por lo que se realizó utilizando el correo electrónico, entre enero de 2010 y mayo de 2010. Los datos obtenidos se verificaron en una muestra aleatoria mediante llamada telefónica.

\section{Ficha de la investigación}

\begin{tabular}{|l|l|}
\hline \multicolumn{1}{|c|}{ Encuesta de opinión } & \multicolumn{1}{|c|}{ Analítica } \\
\hline Muestra: & no probabilística, accesible, voluntaria, estratégica \\
\hline Cuestionario: & $\begin{array}{l}\text { respuesta cerrada, selección múltiple, escala de Likert, } \\
\text { opción única, sencillo (no abandonos) }\end{array}$ \\
\hline Tamaño muestral: & 253 entrevistas \\
\hline Forma: & email \\
\hline Mecánica de seguimiento: & $\begin{array}{l}\text { verificación mediante llamada telefónica a muestra } \\
\text { aleatoria }\end{array}$ \\
\hline
\end{tabular}

Tabla 1

\section{Cuestionario encuesta de opinión}

Las preguntas tratan de conocer la opinión de los encuestados respecto a las siguientes variables:

- Grado de aceptación de la publicidad en el teléfono móvil.

- Facilidad de recuerdo.

- Nivel de comprensión de los mensajes -texto, imagen y sonido-.

- Preferencia de contenidos. 


\section{Resultados}

\subsection{Encuesta de opinión. Frecuencias y porcentajes: gráficos y tablas}

El grupo de referencia analizado en esta investigación está formado por una muestra no probabilística accesible que ha participado de modo voluntario y que representa el perfil genérico de usuarios de teléfonos móviles. De los encuestados, un $69,2 \%$ declara recibir mensajes publicitarios en el teléfono móvil, el $28,1 \%$ no los recibe, y un $2,7 \%$ no sabe o no contesta.

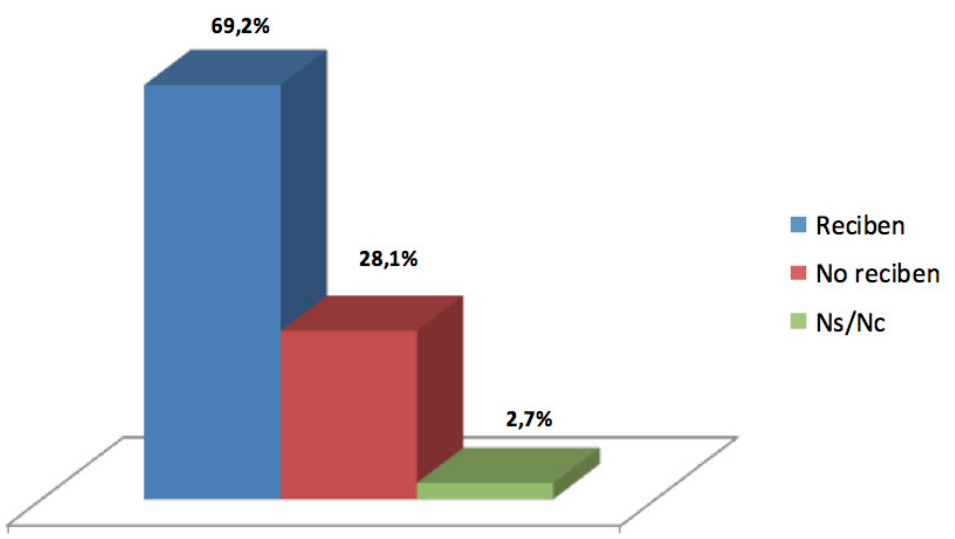

Gráfico 1. Reciben publicidad en el móvil (número de individuos). Fuente: Elaboración propia.

La frecuencia de recepción de anuncios publicitarios varía según la forma en que llegan al terminal.

\begin{tabular}{|l|l|l|l|l|l|}
\hline & \multicolumn{1}{|c|}{ Nunca } & \multicolumn{1}{|c|}{ Alguna vez } & $\begin{array}{c}\text { Una vez } \\
\text { al día }\end{array}$ & $\begin{array}{c}\text { De 2 a 5 } \\
\text { veces al día }\end{array}$ & $\begin{array}{c}\text { Más de 5 } \\
\text { veces al día }\end{array}$ \\
\hline SMS & 0 & $44,0 \%$ & $32,0 \%$ & $12,0 \%$ & $12,0 \%$ \\
\hline MMS & $50,3 \%$ & $33,1 \%$ & $4,6 \%$ & $4,0 \%$ & $8,0 \%$ \\
\hline Llamada & $24,0 \%$ & $40,0 \%$ & $16,0 \%$ & $20,0 \%$ & 0 \\
\hline Bluetooth & $92,0 \%$ & $4,0 \%$ & $4,0 \%$ & 0 & 0 \\
\hline BIDI & $98,3 \%$ & $1,7 \%$ & 0 & 0 & 0 \\
\hline
\end{tabular}

Tabla 2. Datos sobre total que recibe publicidad. Fuente: Elaboración propia. 
Formatos con texto, imagen y sonido en campañas de comunicación persuasiva móvil | 283

Los datos recogidos en esta tabla nos revelan aspectos importantes sobre la publicidad en el móvil: la principal vía de recepción es mediante mensajes SMS, seguida de cerca por las llamadas telefónicas. La recepción de anuncios publicitarios vía bluetooth o en formato bidi es prácticamente nula.

Respecto a nuestra variable de estudio, comprobamos que los anuncios que se reciben con más frecuencia son aquellos que contienen solo texto, seguidos por los que combinan texto e imagen:

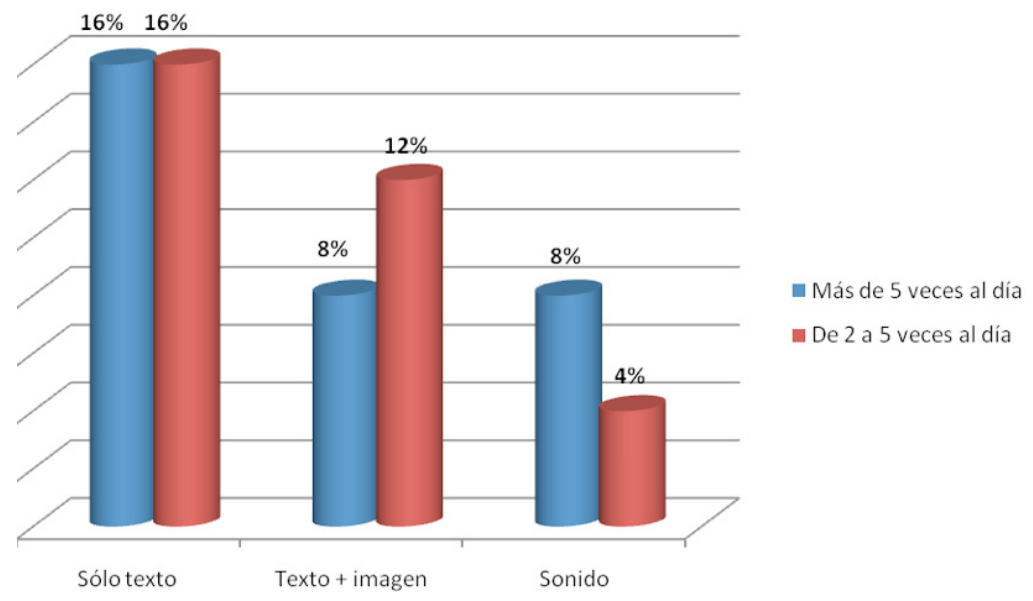

Gráfico 2. Frecuencia de anuncios recibidos (por componentes expresivos).

Fuente: Elaboración propia. Datos sobre total que recibe publicidad. 
Hasta ahora, para la interpretación de los datos, se han utilizado porcentajes con el objeto de describir un tipo de variables que permitían una interpretación absoluta. A partir de este punto, y puesto que se va a comparar valores cuyos resultados se miden en escala, es más pertinente utilizar valores medios para la interpretación, ya que permiten comparar $\mathrm{y}$, de este modo, obtener unas conclusiones más concretas.

Relacionando las medias obtenidas en el estudio en función del componente expresivo, los anuncios con ejecución texto + imagen destacan frente al resto, ya que son los que mejor comprenden los encuestados, y también son los que más gustan.

\begin{tabular}{|l|l|l|}
\hline & \multicolumn{1}{|c|}{ Comprenden } & \multicolumn{1}{c|}{ Gustan } \\
\hline Texto & 2,44 & 1,88 \\
\hline Texto + imagen & 3,20 & 2,24 \\
\hline Texto + imagen + sonido & 2,76 & 2,16 \\
\hline Audiovisuales & 2,52 & 2,20 \\
\hline
\end{tabular}

Tabla 3. Datos sobre total que recibe publicidad. Fuente: Elaboración propia.

El grado de recuerdo de los mensajes publicitarios en el móvil se ha estudiado desde la perspectiva formal:

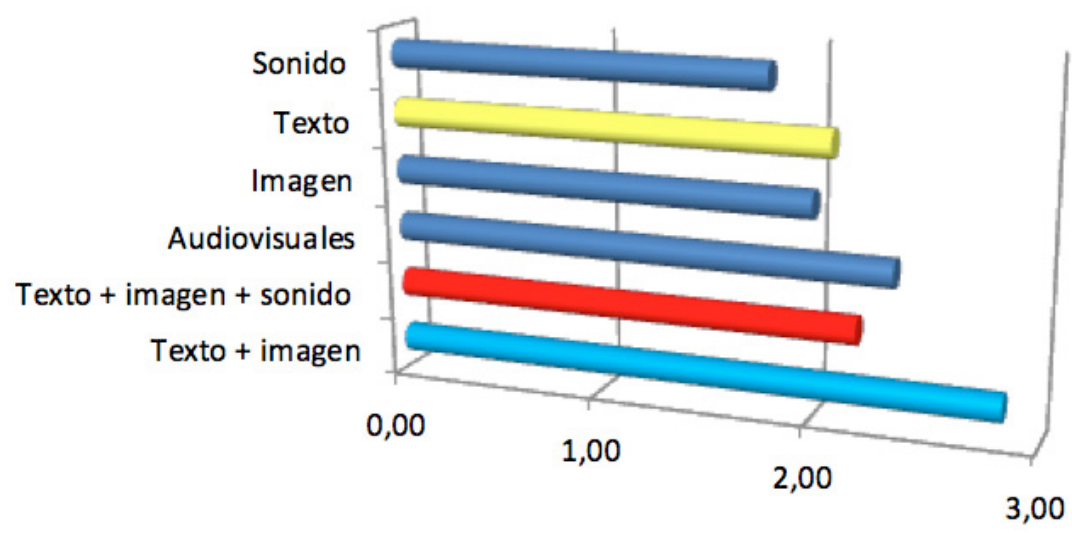

Gráfico 3. Comparativa del grado de recuerdo en función del componente expresivo (medias). Fuente elaboración propia. Datos sobre total que recibe publicidad. 
El formato más recordado es el que combina texto/imagen, seguido de los anuncios audiovisuales y de los construidos con texto/imagen/sonido. Con las medias obtenidas, podemos afirmar que estos tres formatos son adecuados para realizar campañas publicitarias en el móvil. Es interesante reflejar el inferior grado de recuerdo que consiguen los mensajes que solo incorporan texto, sonido o imagen.

\subsection{Análisis e interpretación de datos}

La metodología utiliza el análisis estadístico descriptivo y se implementado el programa Statgraphics, centrado en la exploración de los datos paramétricos y no paramétricos obtenidos de las respuestas de la encuesta. Para este estudio, se ha fijado un nivel de probabilidad del 0,05.

\section{Datos no paramétricos}

Mediante la construcción de tablas de contingencia, se ha calculado el valor JICuadrado de las diferentes variables sometidas a estudio. Esta descripción se centra en el análisis de las relaciones entre aquellas que han aportado un resultado más significativo para el objeto de estudio.

Si se establece una comparación utilizando el componente expresivo, se observa que el grado de recuerdo de la publicidad que combina texto e imagen está relacionado con el grado en que se aceptan estos anuncios. Con un valor $\mathrm{x}^{2}=164,3850$ y 12 grados de libertad, existe una dependencia significativa entre las variables:

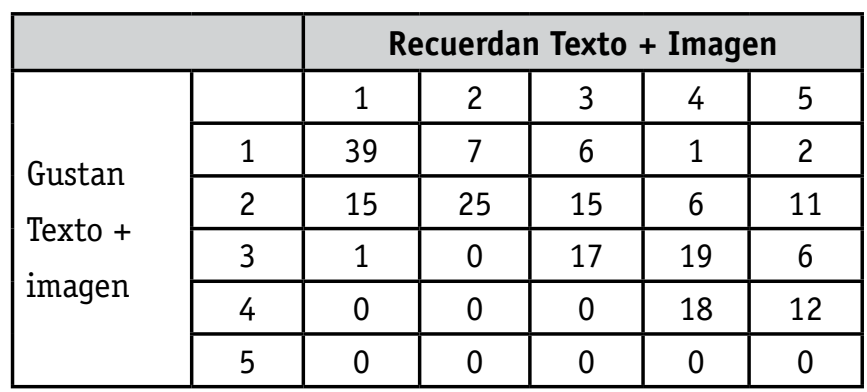

Tabla 3. Datos sobre total que recibe publicidad. Fuente: Elaboración propia. 
Tal como se puede observar en las tablas, el grado de recuerdo y de aceptación de la publicidad en el teléfono móvil son dependientes, y la relación se constata con el análisis de la variable del componente expresivo. En todos los test de independencia realizados se ha establecido un nivel de confianza del $95 \%$.

\section{Datos Paramétricos}

En el análisis de datos paramétricos se han utilizado los siguientes métodos de análisis: prueba de T-Student y correlación de Pearson.

\section{Prueba de T-Student}

Los datos obtenidos permiten afirmar que existe una variación significativa entre hombres y mujeres en cuanto a su comportamiento en relación con las variables sometidas a estudio:

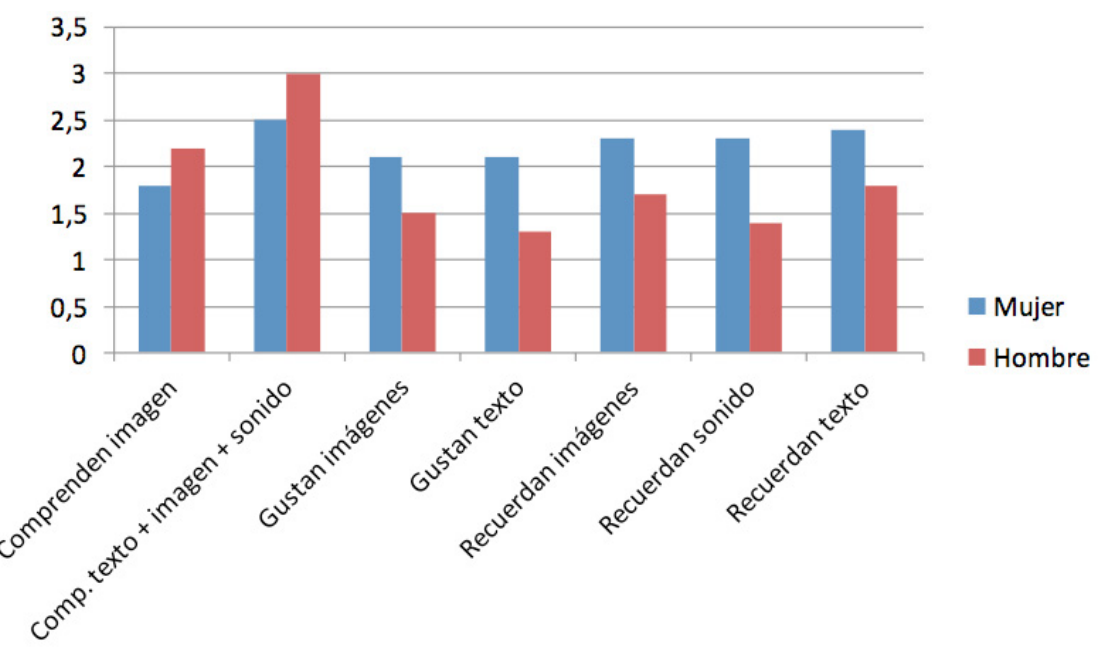

Gráfico 4. Comparación de variables por sexo (medias).

Fuente: Elaboración propia. Datos sobre total que recibe publicidad.

Como se puede observar en el gráfico anterior, las mujeres son más sensibles en todas las variables, a excepción de aquellas que se relacionan con el grado de comprensión, en las que los hombres alcanzan un mayor nivel de entendimiento. 


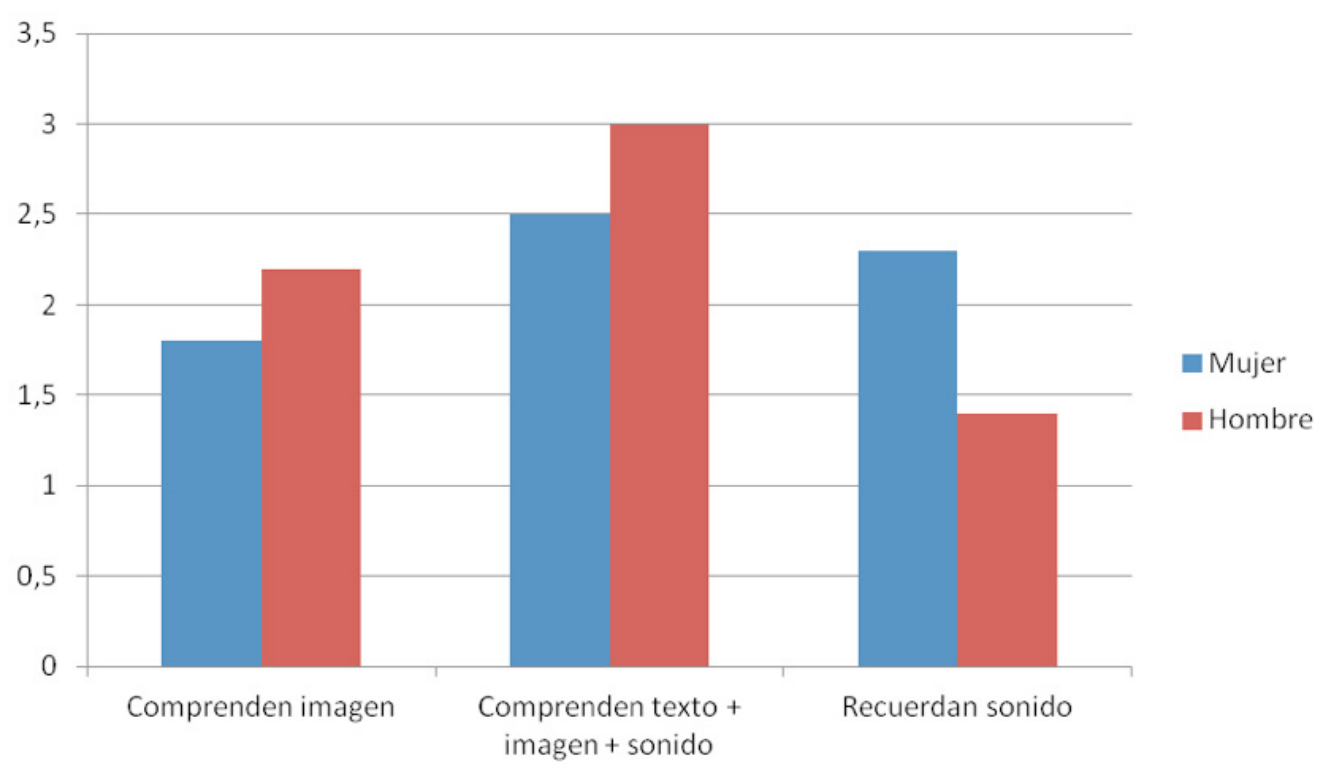

Gráfico 5. Anuncios que recuerdan/comprenden por sexo (medias).

Fuente: Elaboración propia. Datos sobre total que recibe publicidad.

En el gráfico se observa que los entrevistados, en conjunto, comprenden significativamente los anuncios que combinan texto/imagen/sonido, y que el grado de comprensión de los hombres es superior al de las mujeres.

En el caso de anuncios producidos únicamente con sonido, se observan que la tendencia se modifica, y son las mujeres las que más recuerdan, pues la variación muestra un valor negativo.

Si se relaciona el comportamiento de hombres y mujeres respecto a los anuncios en el teléfono móvil, observamos que el sexo condiciona el comportamiento de los receptores de publicidad en el teléfono móvil en relación con las variables sometidas a estudio.

Como dato relevante, se puede afirmar que, en conjunto, las mujeres son más sensibles a la publicidad vía teléfono móvil que los hombres. 


\section{Correlación de Pearson}

En este apartado se estudia la correlación que existe entre dos variables realizando un contraste. Primero, se genera la matriz de correlaciones para realizar un análisis de los datos obtenidos a continuación.

En primer lugar, se ha comparado todas las variables en relación con los SMS y el componente expresivo:

\begin{tabular}{|l|l|l|l|l|l|l|}
\hline & Rec_Img & Rec_Son & Rec_Txt & Rec_Txt img & Rec_Txt img son & Rec_Audiovis \\
\hline Ent_SMS & 0,617 & 0,525 & 0,346 & 0,321 & 0,561 & 0,536 \\
\hline Gust_SMS & $\mathbf{0 , 7 9 5}$ & 0,735 & 0,473 & 0,431 & 0,643 & 0,603 \\
\hline Rec_SMS & 0,720 & 0,483 & $\mathbf{0 , 7 5 3}$ & 0,385 & 0,657 & 0,611 \\
\hline Frec_SMS & 0,098 & $-0,015$ & 0,006 & 0,099 & $-0,038$ & $-0,092$ \\
\hline
\end{tabular}

Tabla 4. Datos sobre total que recibe publicidad. Fuente: Elaboración propia.

Se demuestra que existe una alta correlación entre el grado en que gustan los mensajes publicitarios vía SMS y el grado de recuerdo de los anuncios con un componente expresivo basado en la imagen. Los anuncios realizados con solo texto encuentran correlación en el grado de recuerdo, por lo que se puede afirmar que los anuncios publicitarios vía SMS que más se recuerdan son los que solo incorporan texto.

A continuación, se ha realizado el mismo análisis tomando como referencia los $M M S$, y se obtiene la siguiente tabla:

\begin{tabular}{|l|l|l|l|l|l|l|}
\hline & Rec_Img & Rec_Son & Rec_Txt & Rec_Txt img & Rec_Txt img son & Rec_Audiovis \\
\hline Ent_MMS & 0,500 & 0,366 & 0,261 & 0,459 & 0,361 & 0,331 \\
\hline Gust_MMS & 0,510 & 0,441 & 0,238 & 0,402 & 0,343 & 0,302 \\
\hline Rec_MMS & 0,544 & 0,365 & 0,269 & $\mathbf{0 , 8 0 6}$ & 0,447 & 0,431 \\
\hline Frec_MMS & 0,308 & 0,038 & 0,011 & 0,515 & 0,179 & 0,137 \\
\hline
\end{tabular}

Tabla 5. Datos sobre total que recibe publicidad. Fuente: Elaboración propia.

En los datos de la tabla se comprueba la alta correlación que existe entre el recuerdo de los MMS con los anuncios publicitarios realizados combinando texto e imagen. 
Como reseña general, se puede destacar que la frecuencia de recepción de anuncios publicitarios en el móvil no tiene un nivel de significación relevante respecto a las variables en estudio.

\subsection{Contraste de hipótesis}

Los resultados obtenidos en esta investigación han proporcionado información relevante respecto a las hipótesis planteadas.

\section{Hipótesis:}

- H: La frecuencia de recepción de anuncios publicitarios varía según la forma en que llegan al terminal.

Los datos obtenidos demuestran la validez de la hipótesis por la variedad en porcentaje entre los tipos de recepción que pueden llegar a superar el $90 \%$ en diferencias entre variables tales como SMS, MMS, Bluetooth, etc.

- H: El grado de comprensión de los mensajes publicitarios en el móvil varía en función del componente expresivo y del género.

Los datos obtenidos permiten afirmar que los mensajes publicitarios recibidos en el teléfono móvil que más se recuerdan son los producidos con formato texto/ imagen, con un grado de recuerdo del $92 \%$.

- H: Existe una variación significativa entre hombres y mujeres en cuanto a la recepción de los componentes -texto, imagen y sonido- de los mensajes publicitarios.

Por sexo, se observa que las mujeres son más sensibles a todas las variables, y destaca su capacidad para recordar anuncios sonoros. Los hombres únicamente tienen un mejor comportamiento en relación con la variable comprensión en los anuncios que combinan texto/imagen/sonido o los realizados con imagen.

- H: El grado de recuerdo de los mensajes publicitarios en el móvil varía en función de los componentes expresivos. 
Los datos obtenidos en la investigación también confirman que en cuanto al componente expresivo, los que mejor se entienden son los que combinan texto/ imagen, con un grado de comprensión del $84 \%$, y por formato, los promocionales, con un $88 \%$.

Los resultados verifican la hipótesis, y demuestran que los anuncios publicitarios en el móvil se recuerdan/entienden, y que el grado de recuerdo/comprensión está condicionado por el formato, y el sexo.

La verificación de las hipótesis permite afirmar que el teléfono móvil es un medio que reúne las condiciones necesarias para ser el más utilizado en los próximos años, ya que, además de las características propias que se han constatado que le definen como un medio personal, portátil e interactivo, aglutina condiciones generales esenciales para la publicidad: los mensajes publicitarios en el móvil se aceptan, los anuncios se recuerdan, los contenidos son eficaces, y las vías de transmisión de los mensajes funcionan.

En definitiva, es esencial tener en cuenta el componente expresivo a la hora de diseñar acciones de marketing móvil con el fin de conseguir una publicidad eficaz.

La publicidad en el teléfono móvil es una modalidad altamente eficaz, pero con niveles de coste muy inferiores, se presenta como una opción que hay que tener siempre en cuenta; especialmente, en entornos de situación económica en recesión, como la que vivimos actualmente. Y esto es así no solo por todos los atributos positivos que se han analizado, sino también por su capacidad para ser accesible a presupuestos que necesitan realizar acciones con un ROI elevado, pero invirtiendo presupuestos contenidos.

En conclusión, el teléfono móvil representa para la publicidad un nuevo canal con unas prestaciones que abren unas variadas posibilidades de explotación. 


\section{Discusión}

En la presente investigación se aborda la comunicación a través de un nuevo canal de comunicación como es la telefonía móvil, la cual se ha convertido en un objeto de estudio profusamente estudiado en áreas profesionales y académicas. Cuando se habla de las comunicaciones digitales a través de los medios sociales hay que contextualizarlos en la mayoría de los casos en un entorno móvil, consecuencia de los cambios tecnológicos que se han producido en los últimos años. Esta transformación vertiginosa de la tecnología ha producido nuevas interrelaciones entre los sujetos expuestos a los mensajes, fruto de la evolución constante de las herramientas. Ahora bien, la reflexión sobre las consecuencias psicosociales en la realidad contemporánea producida por los cambios en los canales de comunicación, nos lleva a afirmar la necesidad de una discusión constante sobre la investigación que se realiza en un momento determinado y su pertinencia en un corto periodo de tiempo.

Los cambios tecnológicos están siendo motores de la evolución en muchos aspectos relacionados con los individuos, pero no se puede olvidar que con independencia del medio de comunicación elegido para establecer el intercambio de mensajes, el contenido de estos sigue siendo el elemento troncal que dota de significado la comunicación. Las discusiones futuras deben de tener en cuenta la tecnología y el contenido para realizar una predicción de futuro, lo cual se manifiesta como un reto para el investigador.

En el caso concreto de la investigación que se presenta, el planteamiento de nuevas hipótesis debe de obedecer al interés hacia los sistemas que profundizan en los comportamientos de los sujetos al navegar por los contenidos, y más concretamente, las técnicas basadas en los datos obtenidos de sistemas DATA, y la creación de contenidos no invasivos y con el estilo llamado "Branded Content". Es relevante para el investigador conocer la evolución de las variables que se han tratado en esta investigación, realizando las preguntas de investigación siguientes:

- ¿Cambiará el grado de aceptación de la publicidad en el teléfono móvil?

- ¿Los cambios tecnológicos futuros facilitarán de recuerdo?

- En un futuro, ¿Mejorará el nivel de comprensión de los mensajes?

- ¿Qué contenidos serán los más demandados?

DOI: ri14v12i1.631 | ISSN: 1697-8293 | Año 2014 Volumen 12 N¹ | ICONO14 


\section{Notas}

[1] Source: A.T. Kearney, GSMA Wireless Intelligence, Machina Research. Disponible en: http:// www.atkearney.com/documents/10192/760890/The_Mobile_Economy_2013.pdf

[1] Traducción: "Sin una apropiada medición, realmente no conocemos la eficacia de nuestros esfuerzos. Necesitamos un método para determinar la efectividad de nuestros esfuerzos" (Stengal, 2004).

\section{Referencias}

Arroyo, I. (2004). La creatividad y la razón tecnológica en la argumentación

publicitaria. Creatividad y Sociedad, 6, pp. 27-34. Madrid: Editorial Fundación

Is $+D$ para la investigación social avanzada.

Carrillo, Ma . V. y Castillo, A. (2005). La Nueva Publicidad Digital (NPD): Servicios

Digitales y Contenidos Interactivos que Generen 'Experiencias' en los

Consumidores. Razón y Palabra, 45. México: Editorial Razón y Palabra .

Dance, F. (1973). Teoría de la comunicación humana. Buenos Aires: Ediciones

Troquel.

García García, F. (2005). Una aproximación a la historia de la Retórica. Revista

Icono 14, Año 3. 2005 Vol.1, n5, Retórica. Madrid: Icono 14 Asociación

Científica.

García García, F., Llorente Barroso, C., García Guardia, M.L., (2010). La

construcción globalizada del logosímbolo y la globalización de la marca a través del mismo, Historia y Comunicación Social. Madrid: Ed. Complutense.

Gértrudix, M., García García, F., García Guardia, M. K., (2010). Una tele en el bolsillo: nuevos modelos de representación audiovisual narrativa en soportes de movilidad. Málaga: Ed. ADHOC.

Katz, E. \& Aarhus, M. (2002). Perpetual Contact: Mobile Communication, Private Talk, Public Performance. Cambridge: Cambridge University Press.

López, A., (2000). Esencia y objeto de la retórica. Salamanca: Ediciones

Universidad de Salamanca.

Mourelle de Lema, M. (2003). Ensayo de Teoría General de Comunicación Verbal. Madrid: Ediciones Grugalma.

Wimmer, R. D., Dominick, J. H. (1996). La investigación científica de los medios de comunicación social. Barcelona: Bosch. 